\title{
Concomitant cemento-osseous dysplasia and aneurysmal bone cyst of the mandible: a rare case report with literature review
}

\author{
Han-Gyeol Yeom ${ }^{1}$ and Jung-Hoon Yoon ${ }^{2^{*}}$ (D)
}

\begin{abstract}
Background: Concomitant cemento-osseous dysplasia (COD) and aneurysmal bone cyst (ABC) are rare in the head and neck region. In our search of the English language literature, we found only one case report describing the simultaneous occurrence of $C O D$ and $A B C$ in the head and neck region. Here, we report a case of COD associated with $A B C$. Further, we performed a systematic search of the literature to identify studies on patients with $C O D$ associated with nonepithelial lined cysts of the jaws.
\end{abstract}

Case presentation: The patient was a 32-year-old woman who was referred from a private dental clinic because of a cystic lesion below the mandibular right first molar. She had no pain or significant systemic disease. After performing panoramic radiography and cone-beam computed tomography, the imaging diagnosis was COD with a cystic lesion, such as $A B C$ or solitary bone cyst. Excisional biopsy was performed, which revealed concomitant COD and $A B C$.

Conclusion: This case of $A B C$ associated with COD provides insight for the diagnostic process of radiographically mixed lesions with cystic changes.

Keywords: Aneurysmal bone cyst, Fibro-osseous lesions, Cemento-osseous dysplasia

\section{Background}

Cemento-osseous dysplasia (COD) is a fibro-osseous lesion occurring in the tooth-bearing area of the jaws [1-3]. The etiology and pathogenesis are unknown, but it is thought to arise from the periodontal ligament because of the proximity of the lesions to the teeth and the formation of cementum-like calcifications $[1,3]$. The lesions usually are asymptomatic, so COD is discovered in routine panoramic radiographs, and in most cases, no treatment is necessary [4]. Disease progression can be divided into three stages: osteolytic, mixed, and matured osteogenic [5]. Histopathologically, all forms of COD have a similar appearance; the lesion is not surrounded by a capsule, and

* Correspondence: opathyoon@wku.ac.kr

${ }^{2}$ Department of Oral and Maxillofacial Pathology, Daejeon Dental Hospital, Wonkwang University College of Dentistry, Daejeon, South Korea Full list of author information is available at the end of the article the early osteolytic stage consists of fibrotic tissue rich in cells and vessels, with a little cementum-like deposits [3, 6]. As the maturation progresses over time, cementumlike calcifications and irregular trabeculae appear. In the final osteosclerotic stage, these structures connect to each other, and few cellular elements are visible [6].

The aneurysmal bone cyst $(\mathrm{ABC})$ is a benign, osteolytic, rapidly growing, expansile lesion of the bone, which predominantly occurs in the metaphysis of long bones, such as the femur, tibia, and spine [7, 8]. Its occurrence in the jaws is uncommon [7]. Radiographically, $\mathrm{ABCs}$ are characterized by ballooned cortical expansion from unilocular to multilocular radiolucent lesions [8]. Histopathologically, $\mathrm{ABCs}$ are characterized by bloodfilled spaces, separated by fibrous septa containing osteoclast-like giant cells [8]. The lesion develops either de novo as a true mesenchymal neoplasm, termed 


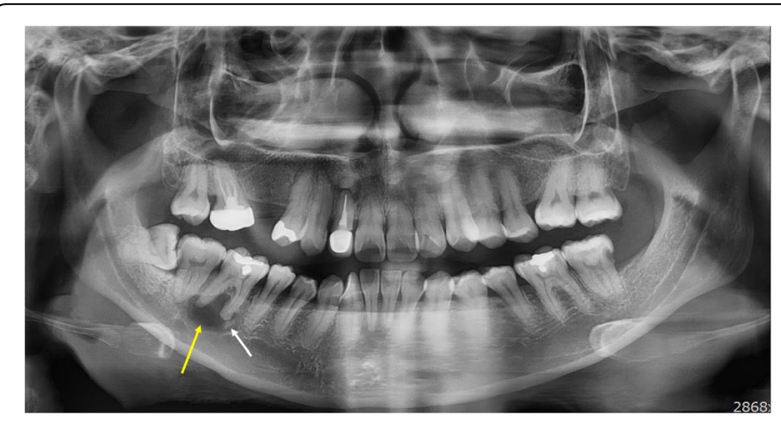

Fig. 1 Panoramic radiograph showing a round mixed lesion below the mandibular right first molar (yellow arrow). The radiopaque portion was observed inside the radiolucent portion (white arrow)

"primary $\mathrm{ABC}$," or secondary to a pre-existing bone lesion, termed "secondary ABC." $[9,10]$ Secondary ABCs demonstrate similar pathologic characteristics as primary $\mathrm{ABCs}$ but have additional histologic findings indicating the presence of an additional coexisting lesion [10]. Approximately $70 \%$ of $\mathrm{ABC}$ cases are primary, whereas $30 \%$ are secondary $[10,11]$.

Nonepithelial lined cysts occasionally occur along with various bone lesions, mainly fibrous dysplasia, giant cell tumor, chondroblastoma, ossifying fibroma, benign osteoblastoma, COD, fibrous histiocytoma, fibrosarcoma [12]. These cysts include $A B C$, simple bone cyst (SBC), and non-specific cystic degeneration [12]. Concomitant $\mathrm{COD}$ and $\mathrm{ABC}$ lesions are rare in the head and neck region. In our search of the English-language literature, we found only one case report describing the occurrence of concomitant $\mathrm{COD}$ and $\mathrm{ABC}$ in the head and neck region [11]. Here, we report a case of COD associated with $\mathrm{ABC}$. ABC associated with a benign fibro-osseous lesion has been investigated in previous studies [11], but no literature review has been conducted for COD associated with a nonepithelial cyst. Therefore, a systematic search of the literature was performed to identify studies reporting patients with COD associated with nonepithelial lined cysts of the jaws.

\section{Case presentation}

The patient was a 32-year-old Korean woman referred because of a cystic lesion below the mandibular right first molar at a local dental clinic. She had no pain or significant systemic disease. Several clinical tests, including electric pulp test, were performed and the affected tooth showed the presence of pulp vitality. There was no tooth mobility.

Panoramic radiography revealed a round, mixed lesion below the mandibular right first molar (Fig. 1). The border of the lesion was clear, but no clear cortication was observed. The effects on the adjacent teeth and inferior alveolar canal were unclear. The lesion was generally radiolucent, but a mixed radiopaque portion was seen adjacent to the anterior boundary of the lesion, resembling the shape of a mixed lesion.

In the additionally obtained cone-beam computed tomography scan, a slightly ovoid lesion was observed anteriorly and backwards (Fig. 2). Likewise, the boundaries were clear, but no clear cortication was observed. Although thinning of the adjacent cortical bone was

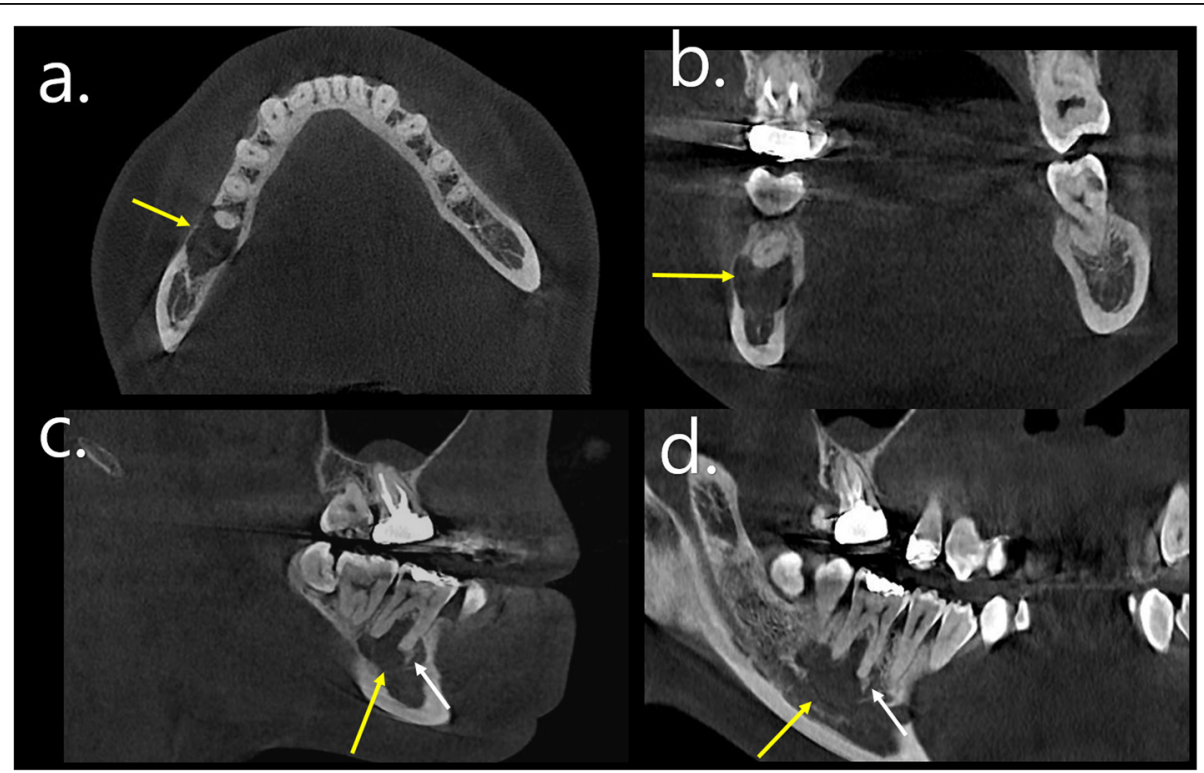

Fig. 2 Cone-beam computed tomography scan of the patient. (a. axial, b. coronal, c. sagittal, d. panoramic view) A slightly ovoid lesion was observed anteriorly and backwards (yellow arrow). No apparent expansion pattern or deviation of the adjacent structures was observed. The radiopaque portion was observed inside the radiolucent portion (white arrow) 


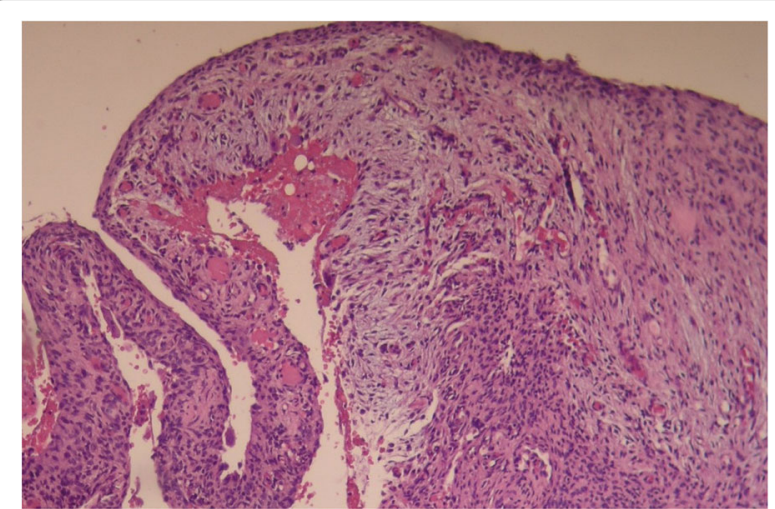

Fig. 3 Cystic aneurysmal components show blood-filled cystic cavities lined with a thick membranous structure that comprises multinucleated giant cells. (H \& E stain)

observed, no apparent expansion pattern was observed. The radiopaque portion inside the radiolucent portion was mixed at the anterior site of the lesion. The anterior part of the lesion showed the characteristics of COD. The middle and posterior parts of the lesion were suspected of cystic changes, showing low attenuation. The size of the area considered as a cystic portion was not sufficiently large, so it was difficult to distinguish it as a secondary cystic lesion. Considering all radiologic findings, the imaging diagnosis was COD with a cystic lesion, such as $\mathrm{ABC}$ or SBC.

Surgical excision and histopathologic examination were performed. Histopathologically, stromal tissue was composed of spindle-shaped fibroblasts with small blood vessels (Fig. 3). Cystic aneurysmal components showed blood-filled cystic cavities lined with a thick membranous structure that comprised multinucleated giant cells and mononuclear cells (Fig. 4). The anterior part of the lesion showed a sclerotic mass of cemento-osseous material (Figs. 5, 6). Considering both histopathological and

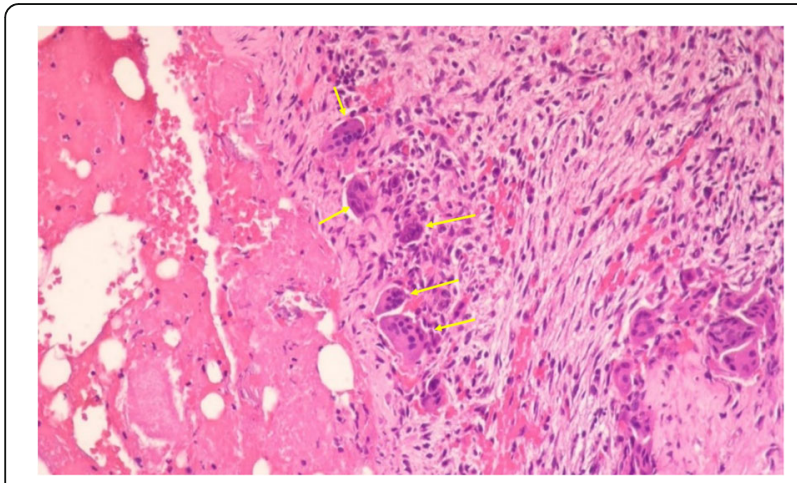

Fig. 4 Cystic aneurysmal components composed of blood-filled spaces separated by connective tissue septa containing fibroblasts, osteoclast-type giant cells (yellow arrow).(H \& E stain)

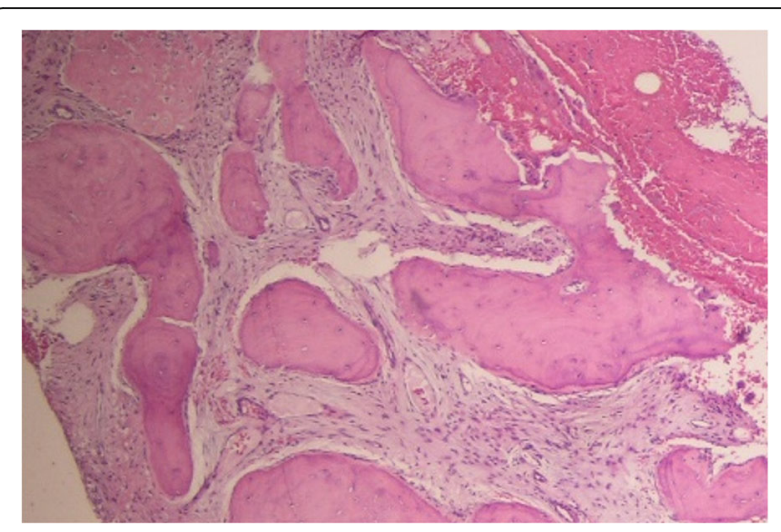

Fig. 5 Anterior part of the lesion shows a sclerotic mass of cemento-osseous material. Stromal tissue is composed of spindleshaped fibroblasts with small blood vessels (H \& E stain)

radiographic properties, the final diagnosis was concomitant COD and ABC.

One-year follow-up was done and there was no evidence of recurrence. Normal bone healing was seen without pathological findings.

\section{Discussion and conclusions}

A systematic search of the literature was performed to identify studies reporting patients with COD associated with nonepithelial lined cysts of the jaws. English- and non-English-language papers were searched in PubMed/ MEDLINE/Google Scholar databases and the gray literature using a combination of terms containing "cementoosseous dysplasia" and containing "aneurysmal bone cyst" or "simple bone cyst" or "traumatic bone cyst" or "cyst" or "cystic lesion." The search was carried out using the literature from 1985 to date. The focus of each reference varied, including a series of patients, case reports, and articles investigating the imaging appearance. Papers that reported epithelial lined cysts, such as a

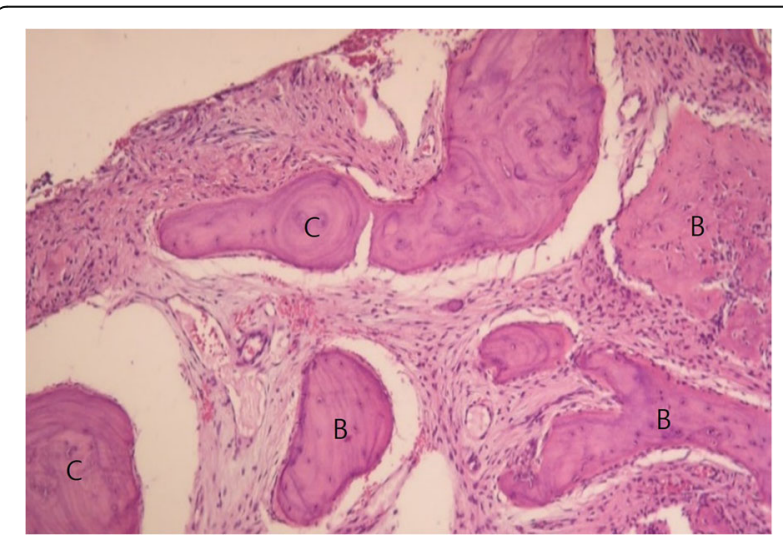

Fig. 6 Cellular fibrous stroma contains an admixture of irregular trabeculae of bone and rounded globules of cementum-like material (C: cementicle, B: osseous portion). ( $H$ \& E stain) 
periapical cyst or dentigerous cyst, were excluded. We reviewed 116 papers and finally selected 14 . Table 1 summarizes the data of the available papers.

We found 46 patients with a female predilection (43 women vs 3 men). Forty-five patients had concomitant COD and SBC, while only one patient had concomitant $\mathrm{COD}$ and $\mathrm{ABC}$. The mean age was 43.47 years, ranging from 11 to 66 years. The mandibular posterior area (premolar, molar, retromolar, and ramus areas) was the most frequently reported site (21 cases: mandibular posterior area; 2 cases: mandibular canine; 23 cases: not mentioned). Clinically, 11 patients presented with pain, while 12 patients presented with no pain. The pain status of 23 patients was not mentioned.

Both $\mathrm{COD}$ and $\mathrm{ABC}$ are non-neoplastic intraosseous lesions. The concomitant occurrence of these lesions could be explained by the probable pathogenesis of $\mathrm{ABC}$. The stroma of COD often displayed characteristic cavernous-like vascularity that was almost always associated with bony trabeculae [6]. Free hemorrhage was frequently interspersed in the artifactual spaces throughout COD [6]. ABC formation could be attributed to a local circulatory disturbance causing a markedly elevated venous pressure and the development of enlarged vascular spaces within the affected bone $[7,25]$. This hemodynamic disturbance could be secondary to local trauma or the presence of a pre-existing lesion in the affected bone [7, 25]. Clinically, COD usually presents slow-growing, painless lesions, whereas the $\mathrm{ABC}$ presents a rapidly growing, painful lesion. Our patient had no pain, but the radiograph revealed a lesion.

Our literature search demonstrated only one case report of concomitant $\mathrm{COD}$ and $\mathrm{ABC}[11]$, so an accurate analysis is difficult with only two cases. Both patients were women, and the ages were 32 and 41 years, respectively. In case of concomitant COD with a cystic lesion, $\mathrm{SBC}$ was reported as a cystic lesion more than $\mathrm{ABC}$. The $\mathrm{SBC}$ is a pseudocyst similar to $\mathrm{ABC}$ in various aspects:

Table 1 Summary of literature review: patients with COD associated with nonepithelial lined cysts of the jaws

\begin{tabular}{|c|c|c|c|c|c|c|c|c|}
\hline Authors & Year & Concomitant & $\begin{array}{l}\text { Sample } \\
\text { size }\end{array}$ & Sex & $\begin{array}{l}\text { Age } \\
\text { (years) }\end{array}$ & Site & Pain & Treatment \\
\hline \multirow[t]{4}{*}{ Higuchi et al. [13] } & 1988 & $\mathrm{COD} \& \mathrm{SBC}$ & 4 & $\mathrm{~F}$ & 40 & Left third molar & $\mathrm{N}$ & Excision \\
\hline & & & & $\mathrm{F}$ & 31 & Left second molar & $\mathrm{N}$ & Excision \\
\hline & & & & $\mathrm{F}$ & 42 & Left second premolar to left second molar & $\mathrm{N}$ & Excision \\
\hline & & & & $\mathrm{F}$ & 49 & Left canine & $\mathrm{N}$ & Excision \\
\hline Miyauchi et al. [14] & 1995 & $C O D \& S B C$ & 1 & $\mathrm{~F}$ & 40 & $\begin{array}{l}\text { Right premolar-retromolar/right canine to left first } \\
\text { premolar }\end{array}$ & Y & Excision \\
\hline Wakasa et al. [15] & 2002 & $\mathrm{COD} \& \mathrm{SBC}$ & 1 & $\mathrm{~F}$ & 34 & $\begin{array}{l}\text { Right retromolar/right premolar-molar/left premolar- } \\
\text { central incisor/left molar }\end{array}$ & Y & Curettage \\
\hline Mupparapu et al. [16] & 2005 & $\mathrm{COD} \& \mathrm{SBC}$ & 1 & $\mathrm{~F}$ & 41 & Right premolar-molar & $\mathrm{N}$ & Curettage \\
\hline \multirow[t]{7}{*}{ Mahomed et al. [17] } & 2005 & $C O D \& S B C$ & 7 & $\mathrm{~F}$ & 43 & Right molar & Y & Excision \\
\hline & & & & $\mathrm{F}$ & 54 & Left ramus-right ramus & Y & Excision \\
\hline & & & & $\mathrm{F}$ & 48 & Left molar to right molar & $\mathrm{N}$ & Excision \\
\hline & & & & $\mathrm{F}$ & 26 & Right molar & $\mathrm{N}$ & Excision \\
\hline & & & & $\mathrm{F}$ & 35 & Left third molar & Y & Excision \\
\hline & & & & $\mathrm{F}$ & 48 & Both molars & Y & Excision \\
\hline & & & & $\mathrm{F}$ & 42 & Right molar & Y & Excision \\
\hline Mupparapu et al. [18] & 2008 & $\mathrm{COD} \& \mathrm{SBC}$ & 1 & $\mathrm{~F}$ & 39 & Right mandibular/left mandibular 2 & Y & Curettage \\
\hline \multirow[t]{3}{*}{ Martini et al. [19] } & 2010 & $\mathrm{COD} \& \mathrm{SBC}$ & 3 & $\mathrm{~F}$ & 66 & Left mandibular molar & $\mathrm{N}$ & - \\
\hline & & & & $\mathrm{F}$ & 11 & Left premolar-molar & $\mathrm{N}$ & - \\
\hline & & & & $\mathrm{F}$ & 42 & Left premolar-molar & $\mathrm{N}$ & - \\
\hline Rao et al. [20] & 2011 & $C O D \& S B C$ & 1 & $\mathrm{~F}$ & 41 & Right molar & Y & Excision \\
\hline \multirow[t]{2}{*}{ Chadwick et al. [21] } & 2011 & $\mathrm{COD} \& \mathrm{SBC}$ & 23 & $\mathrm{~F}-20$ & 47 & - & - & - \\
\hline & & & & $M-3$ & 41.5 & - & - & - \\
\hline Eroglu et al. [22] & 2016 & $\mathrm{COD} \& \mathrm{SBC}$ & 1 & $\mathrm{~F}$ & 23 & Left premolar & $\mathrm{N}$ & Decompression \\
\hline Jacomacci et al. [1 1] & 2017 & $C O D \& A B C$ & 1 & $\mathrm{~F}$ & 41 & Right premolar & $\mathrm{N}$ & Excision \\
\hline Singer et al. [23] & 2019 & $\mathrm{COD} \& \mathrm{SBC}$ & 1 & $\mathrm{~F}$ & 59 & Anterior mandible & Y & Excision \\
\hline Chinckr et al. [24] & 2020 & $C O D \& S B C$ & 1 & $\mathrm{~F}$ & 40 & Right mandibular body & Y & Saucerization \\
\hline
\end{tabular}


most frequently found in the long bones $(50 \%)$ and spine (20\%) but rarely in the jaw bones (2\%). However, the entity of $\mathrm{ABC}$ tends to have a more aggressive clinical behavior compared to SBC.

Compared to one previously reported concomitant $\mathrm{COD}$ and $\mathrm{ABC}$ case, our patient showed the anterior part of the mixed lesion and the posterior cystic portion. Buccolingual expansion was unclear in the cystic portion. Since the cystic portion was small, it was difficult to distinguish $\mathrm{ABC}$ or $\mathrm{SBC}$ in the radiologic findings. Pathologically, the COD portion was observed on one side, and most of the lesions showed the characteristics of $\mathrm{ABC}$. The part where the COD was clearly diagnosable was considered to be the anterior part of the lesion observed in the radiologic mixed lesion.

The imaging findings of the previous case showed the characteristics of $\mathrm{ABC}$ with clear buccolingual expansion. In the pathologic findings presented, the characteristics of COD were generally observed, and in some of them, the $\mathrm{ABC}$ findings were visible. Both lesions were diagnosed as concomitant $\mathrm{COD}$ and $\mathrm{ABC}$, but the imaging and pathologic findings showed some differences among similar tendencies. Although there are various limitations to generalization due to the small number of cases, so, but we are expecting to better understand and diagnose nonepithelial cystic lesions associated with COD by reporting this case, in which an $A B C$ and $C O D$ were present in association.

\section{Abbreviations}

COD: Cemento-osseous dysplasia; ABC: Aneurysmal bone cyst; SBC: Simple bone cyst

\section{Acknowledgments}

Not applicable.

\section{Authors' contributions}

This study was conceived by J.H.Y. who also analyzed and interpreted the histopathologic data. H.G.Y. interpreted the radiologic data and wrote the manuscript. All authors read and approved the manuscript.

\section{Funding}

This work was supported by grants from the Foundation of Wonkwang University in 2020. The funder had no role in the design of the study, the collection, analysis and interpretation of the data, and in writing the manuscript.

\section{Availability of data and materials}

All data analyzed during this study are included in this published article.

Ethics approval and consent to participate

The study was approved by the Institutional Review Board of Daejeon Dental Hospital, Wonkwang University (W2005/002-001).

\section{Consent for publication}

Written informed consent was obtained from the patient for publication of this case report and any accompanying images.

\section{Competing interests}

The authors declare that they have no competing interests.

\section{Author details}

'Department of Oral and Maxillofacial Radiology, Daejeon Dental Hospital, Wonkwang University College of Dentistry, Daejeon, South Korea.

2Department of Oral and Maxillofacial Pathology, Daejeon Dental Hospital, Wonkwang University College of Dentistry, Daejeon, South Korea.

Received: 4 June 2020 Accepted: 24 September 2020

Published online: 09 October 2020

\section{References}

1. Brody A, Zalatnai A, Csomo K, Belik A, Dobo-Nagy C. Difficulties in the diagnosis of periapical translucencies and in the classification of cementoosseous dysplasia. BMC Oral Health. 2019;19(1):139.

2. Ariji Y, Ariji E, Higuchi Y, Kubo S, Nakayama E, Kanda S. Florid cementoosseous dysplasia: radiographic study with special emphasis on computed tomography. Oral Surg Oral Med Oral Pathol. 1994;78(3):391-6.

3. Summerlin DJ, Tomich CE. Focal cemento-osseous dysplasia: a clinicopathologic study of 221 cases. Oral Surg Oral Med Oral Pathol. 1994;78(5):611-20.

4. MacDonald-Jankowski DS. Florid cemento-osseous dysplasia: a systematic review. Dentomaxillofac Radiol. 2003;32(3):141-9.

5. Daviet-Noual V, Ejeil AL, Gossiome C, Moreau N, Salmon B. Differentiating early stage florid osseous dysplasia from periapical endodontic lesions: a radiological-based diagnostic algorithm. BMC oral health. 2017;17(1):161.

6. Su L, Weathers DR, Waldron CA. Distinguishing features of focal cementoosseous dysplasias and cemento-ossifying fibromas: I. a pathologic spectrum of 316 cases. Oral Surg Oral Med Oral Pathol Oral Radiol Endod. 1997;84(3):301-9.

7. Rau LH, Reinheimer A, Meurer MI, Marodin AL, Espezim CS, Klüppel LE, et al. Fibrous dysplasia with secondary aneurysmal bone cyst-a rare case report and literature review. Oral Maxillofac Surg. 2019;23(1):101-7.

8. Motamedi MHK. YazdiE. Aneurysmal bone cyst of the jaws: analysis of 11 cases. J Oral Maxillofac Surg. 1994;52(5):471-5.

9. Martinez V, Sissons HA. Aneurysmal bone cyst. A review of 123 cases including primary lesions and those secondary to other bone pathology. Cancer. 1988:61(11):2291-304.

10. Cottalorda J, Bourelle S. Modern concepts of primary aneurysmal bone cyst. Arch Orthop Trauma Surg. 2007;127(2):105-14

11. Jacomacci WP, Veloso Perdigão JP, Veltrini VC, Farah GJ, Tolentino ES, Vessoni Iwaki LC, et al. Associated aneurysmal bone cyst and cementoosseous dysplasia: a case report and review of the literature. Gen Dent. 2017;65(1):28-32.

12. Ferretti $\mathrm{C}$, Coleman $\mathrm{H}$, Altini M. Cystic degeneration in fibrous dysplasia of the jaws: a case report. Oral Surg Oral Med Oral Pathol Oral Radiol Endod. 1999;88(3):337-42

13. Higuchi Y, Nakamura N, Tashiro H. Clinicopathologic study of cementoosseous dysplasia producing cysts of the mandible: report of four cases. Oral Surg Oral Med Oral Pathol. 1988;65(3):339-42.

14. Miyauchi M, Ogawa I, Takata T, Ito H, Nikai H, Ljuhin N, Tanimoto K. Florid cemento-osseous dysplasia with concomitant simple bone cysts: a case in a Japanese woman. J Oral Pathol Med. 1995;24(6):285-7.

15. Wakasa T, Kawai N, Aiga H, Kishi K. Management of florid cemento-osseous dysplasia of the mandible producing solitary bone cyst: report of a case. J Oral Maxillofac Surg. 2002;60(7):832-5.

16. Mupparapu M, Singer SR, Milles M, Rinaggio J. Simultaneous presentation of focal cemento-osseous dysplasia and simple bone cyst of the mandible masquerading as a multilocular radiolucency. Dentomaxillofac Radiol. 2005; 34(1):39-43

17. Mahomed F, Altini M, Meer S, Coleman H. Cemento-osseous dysplasia with associated simple bone cysts. J Oral Maxillofac Surg. 2005;63(10): 1549-54.

18. Mupparapu M, Milles M, Singer SR, Rinaggio J. Rare, simultaneous, multiple, and recurrent mandibular bone cysts. Quintessence Int. 2008;39(4):331-6.

19. Martini MZ, Rocha AC, Lemos CA, Alves FA. Fibro-osseous lesions associated with simple bone cysts: three case reports and review of the literature. Minerva Stomatol. 2010;59(11-12):671-6.

20. Rao KA, Shetty SR, Babu SG, Castelino RL. Co-occurence of florid cementoosseous dysplasia and simple bone cyst: a case report. J Oral Maxillofac Res. 2011;2(3):e5. 
21. Chadwick JW, Alsufyani NA, Lam EWN. Clinical and radiographic features of solitary and cemento-osseous dysplasia-associated simple bone cysts. Dentomaxillofac Radiol. 2011;40(4):230-5.

22. Eroglu CN, Kaplan N. Cystic process during the follow-up of a focal cemento-osseous dysplasia. J Case Rep Images Dent. 2016;2:28-32.

23. Singer SR, Kashikar S. Florid Cemento-osseous dysplasia with associated simple bone cyst: a case report. N Y State Dent J. 2019;85(6):26-31.

24. Chinckr CDP, Tinoco LVC, De Souza DF, Pinheiro TN. Large simple bone cyst with florid cemento-osseous dysplasia a case report. Oral Surg Oral Med Oral Pathol Oral Radiol. 2020;129(1):e50.

25. Yuen VH, Jordan DR, Jabi M, Agbi C. Aneurysmal bone cystassociated with fibrous dysplasia. Ophthal Plast Reconstr Surg. 2002;18:471-4.

\section{Publisher's Note}

Springer Nature remains neutral with regard to jurisdictional claims in published maps and institutional affiliations.

Ready to submit your research? Choose BMC and benefit from:

- fast, convenient online submission

- thorough peer review by experienced researchers in your field

- rapid publication on acceptance

- support for research data, including large and complex data types

- gold Open Access which fosters wider collaboration and increased citations

- maximum visibility for your research: over $100 \mathrm{M}$ website views per year

At $\mathrm{BMC}$, research is always in progress.

Learn more biomedcentral.com/submissions 